\title{
Assessment of plasticity and stability of grain sorghum varieties on the basis of their grain yield
}

\author{
O. Antimonova*, L. Syrkina, A. Antimonov, and L. Kosykh
}

Volga Research Institute of Breeding and Seed Production named after P.N. Konstantinov of the Samara Scientific Center of the Russian Academy of Sciences, Ust-Kinelsky, Samara region, 446442, Russia

\begin{abstract}
Assessment of adaptability, environmental plasticity and stability of crop varieties in different climatic conditions is an important direction of the selection process. The purpose of the research was to assess the ecological plasticity and stability of 5 varieties (Premiera, Slavyanka, Ros, Kinelskoye 63, Dershavnoe) and 3 lines (L-28/14, L-141/14, L 34/14) of grain sorghum, to identify the role of abiotic factors in the dynamics of its grain yield at the final stages of selection in the competitive testing of varieties. The studies were carried out in the forest-steppe of the Samara region in experimental fields and in the laboratories of the Volga Research Institute of Breeding and Seed Production in 2015-2018 according to the dispersion methods of A.V. Kilchevsky and L.V. Khotyleva, S.A. Eberhart and W.A. Russel. According to the ecological plasticity variety Ros and line L-34/14 were of intensive type. Varieties Derzhavhoe, Kinelskoye 63, Slavyanka and line L-28/14 belonged to the semi-intensive type. Variety Premiera and line L-141/14 were of extensive type. The combination of high productivity and stability was observed in varities Kinelskoye 63, Derzhavnoe, L-28/14 with high parameters of breeding value of genotype. Promising sample L-28/14 with high productivity and environmental stability is recommended for transfer to the state variety testing.
\end{abstract}

\section{Introduction}

Adaptive selection includes a set of methods for obtaining varieties and hybrids of crops with maximum and sustainable productivity in regional environmental conditions. The main issue of adaptive breeding is the problem of accounting for the interaction of genotype and environment. It has two main aspects: assessment of adaptive capacity and genotype stability in different natural conditions and their suitability as a background for selection $[1,2]$. In regions with unfavorable climatic factors, this problem is particularly relevant, since modern varieties must be not only high-yielding, but also highly adaptive. Adaptive breeding is based on the creation of varieties that combine high potential yield and environmental sustainability [3].

Samara region is located in the South-East of the European part of Russia, in the middle reaches of the Volga river, mainly on its left Bank (91.2 \%). The climate of the region is characterized by cold and snowless winter, short spring, hot and dry summer. The climate of the Samara region is characterized by aridity, high continentality, intensive wind activity, high insolation and high variability from year to year, especially in the amount of precipitation. Annual precipitation increases from $270 \mathrm{~mm}$ in the South to 450 $\mathrm{mm}$ in the North of the region. The hydrothermal coefficient is $0.6-0.7,0.8-0.9$ and $1.0-1.1$ in the southern, central and northern zones of the region, respectively. The sum of effective temperatures ranges from $2200{ }^{\circ} \mathrm{C}$ in the North to $2800{ }^{\circ} \mathrm{C}$ in the South of the region. The duration of the frost-free period is 125-140 days [4]. Often, such conditions lead to a significant reduction in the yield of varieties of forage crops. Grain sorghum has a high useful potential, unpretentiousness and feed value, the ability to form a high yield in all weather conditions and occupies an important place among such crops [5-8].

Grain sorghum contains 70-75\% starch, 9-15\% protein, $3.5 \%$ fat and it is a good concentrated feed for all kinds of livestock, poultry and fish. One hundred $\mathrm{kg}$ of sorghum grain contains $118-120 \mathrm{~kg}$ of fodder units. Sorghum grain also contains 17 essential amino acids, vitamins (E1, B1, B2, B3), carotene, minerals $\left(\mathrm{P}_{2} \mathrm{O}_{5}\right.$, $\mathrm{K}_{2} \mathrm{O}$ and $\mathrm{MgO}$ ), tannins. Grain sorghum is tested for use in the food industry in Russia [5, 7, 9]. In 2018, the acreage of sorghum in Russia amounted to 71200 ha, including 3900 ha $(5.5 \%)$ in the Samara region. In Russia, sorghum crops occupy the largest areas in the Saratov (37.1 \%), Orenburg (16.6\%), Volgograd $(16.4 \%)$ and Rostov $(11.5 \%)$ regions.

Samara region is the extreme northern zone of sorghum cultivation. Introduction and comparative study of varieties from more southern regions of Russia showed their instability in grain yield due to their late maturity in the Samara region. This led to the need to create varieties adapted to local conditions. 
Since 1993, the direction of creating varieties of grain sorghum, maturing in the Middle Volga region and able to provide a stable grain yield has developed in the Volga research Institute of breeding and seed production. Although sorghum is considered a drought-resistant and heat-resistant crop, it is important to know its adaptive potential, which characterizes the ecological plasticity and resistance of varieties to environmental conditions in the forest-steppe of the Middle Volga region. Limiting factors of the region should determine the selection of varieties for cultivation. In the same conditions, it is necessary to select the source material at the early stages of selection. The selection criterion should be specific adaptation to stressful conditions and, first of all, to the regional type of drought [8].

The plasticity of a variety is its ability to form a satisfactory yield when grown in different conditions. Variety stability is an indicator of its stability in the implementation of selection and genetic properties of the genotype [10]. Long and painstaking breeding work allows you to get a variety with a complex of economically valuable features, including adaptability to external conditions. Scientists have developed various methods for assessing the parameters of ecological plasticity, which differ from each other in the specifics of calculations and analysis of the results, which provide additional information for the selection of valuable source material in plant breeding for adaptability.

The method of S.A. Eberhart et al. [11] is based on the calculation of the linear regression coefficient (bi), (indicator of genotype response to changes in environmental conditions) characterizing the ecological plasticity of the variety, and the mean square deviation from the regression line $\left(S^{2} d\right)$, which determines the stability of the variety in different environmental conditions. The proposed method of stability assessment makes it possible to show the ability of the genotype to provide a high potential yield with a minimum decrease in productivity under adverse conditions.

The method of genetic analysis developed by A.V. Kilchevsky et al. [1] allows revealing both general and specific adaptive stability (GAS and SAS) and selection value of genotype (SVG), which allows obtaining information about media and interaction "genotype-environment" as backgrounds for selection in plant breeding.

In Russia [1, 3, 12-18] and other countries [11, 19-26], the leading breeders attached great importance to adaptive selection in their studies. Assessment of adaptability, ecological plasticity and stability of varieties by different methods, their application in different climatic conditions is an actual direction of the selection process.

The purpose of our research is to assess the environmental plasticity and stability of varieties and lines of grain sorghum, to identify the role of environmental factors in the variation of grain yield at the final stages of selection in competitive variety testing.

\section{Materials and methods}

The research was carried out in the forest-steppe zone of the Samara region at the facilities of the Volga Research Institute of Breeding and Seed Production in the laboratory of selection and seed production of cereals and sorghum crops in 2015-2018. The geographical location of the experimental site: latitude: $53^{\circ} 13^{\prime} 32$ " N, longitude: $50^{\circ} 37^{\prime} 44^{\prime \prime} \mathrm{E}$, height above sea level: $38 \mathrm{~m}$. The soil of the experimental plots was ordinary chernozem, heavy loam. The varieties of grain sorghum Premiera, Slavyanka, Ros, Kinelskoye 63, Derzhavnoe obtained in the Volga Research Institute of Breeding and Seed Production, and selective lines L-28/14, L-141/14, L-34/14 were used as the object of the study. Sorghum sowing was carried out in the optimal time, at the beginning of the third decade of May according to zonal technology. The experiment was carried out according to the method of State variety testing [29], the area of plots $25 \mathrm{~m}^{2}$ in three-fold repetition, the predecessor was spring barley. The seeding rate was 0.8 million germinating seeds per ha. The development of sorghum and its yield were influenced mainly by hydrothermal conditions, which were estimated during the growing season of the crop by the hydrothermal coefficient (HTC) according to Selyaninov [30], calculated by the formula:

$$
H T C=\frac{\Sigma / R}{0.1 \Sigma t^{0}>10^{0}},
$$

where $\sum R$ is the sum of precipitation, $\sum t^{\circ}>10^{\circ}$ is the sum of the average daily temperatures for the period with a temperature above $10{ }^{\circ} \mathrm{C}$. The integral indicator of the influence of hydrothermal conditions on the development of sorghum was its yield.

Assessment of plasticity and stability of grain sorghum varieties was calculated on the basis of experimental data of the nursery of competitive variety testing on the contribution of the factor "year", on the basis of "grain yield". All varieties of sorghum were studied in conditions of natural soil fertility without the use of plant protection against harmful organisms. Parameters of ecological plasticity and stability of varieties were evaluated by the methods of S.A. Eberhart et al. [11] and A.V. Kilchevsky et al. [1], which provide for the calculation of the genotype response to changes in environmental conditions (2015-2018). Mathematical treatment of sorghum yield was carried out by two-factor dispersion analysis [31].

The method of S.A. Eberhart et al. [11] is based on the calculation of the linear regression coefficient $\left(b_{i}\right)$, which characterizes the ecological plasticity of the variety, and the mean quadrate deviation from the regression line $\left(\mathrm{S}_{\mathrm{i}}{ }_{\mathrm{i}}\right)$, which determines the stability of the variety in different environments. Initially you need to define the environment condition indexes $\left(\mathrm{I}_{\mathrm{j}}\right)$ :

$$
I_{j}=\frac{\sum X_{i j}}{V}-\frac{\sum \sum X_{i j}}{V \cdot n},
$$

where $\sum X$ is the sum of the yield of all varieties for the jth year;

$\sum \sum X$ is the sum of the yield of all varieties for all years;

$v$ is the number of varieties;

$n$ is the number of years of testing. 
To calculate the linear regression coefficient (bi) the formula is used:

$$
b_{i}=\frac{\sum X_{i j} \cdot I_{j}}{\sum I_{j}^{2}},
$$

where $\sum X_{i j} \cdot I_{j}$ is the sum of the product of the yield of the $i$-th variety for the $j$-th year by the corresponding value of the index of environmental conditions;

$\sum I^{2}{ }_{j}$ is the sum of squares of indices of environment conditions.

The theoretical yield required to determine the stability of the yield is calculated by the formula:

$$
Y_{i j}=X_{i}+b_{i} I_{j}
$$

where $X_{i}$ is the average yield of the i-th variety for the years of testing;

$b_{i}$ is regression coefficient;

$I_{j}$ is index of environmental conditions.

The deviation of the actual yield from the theoretical is determined by the formula:

$$
\sigma_{i j}=X_{i j}-Y_{i j}
$$

where $X_{i j}$ is actual yield of the i-th variety in the j-th year;

$Y_{i j}$ is theoretical yield of the i-th variety in the j-th year.

The stability coefficient (variance) was calculated by the formula:

$$
\mathrm{s}_{\mathrm{d}_{\mathrm{i}}}^{2}=\frac{\sum \sigma_{\mathrm{ij}}^{2}}{\mathrm{n}-2}
$$

where $\sum \sigma^{2} i j$ is the sum of squares of deviations of actual yield from theoretical one;

$n$ is the number of varieties and lines.

The method of determining ecological plasticity and stability according to A.V. Kilchevsky et al. [1] allows to determine the general adaptive capacity (GAC) and specific adaptive capacity (SAC) of genotypes, their stability and breeding value for population assessment and selection of methods and directions of breeding research. SAC characterizes the average value of the trait in different environments, SAC - deviation from the GAC in a particular environment. In our experiments, we estimated the GAC by the average yield of sorghum varieties and lines in 2015-2018, and the SAC by the deviation of the yield in a particular year from the average for the years of research.

According to this method, it is initially necessary to establish the fact of the presence or absence of interaction "genotype $\mathrm{x}$ environment" for the entire set of the studied varieties with using of two-factor analysis of variance. Significant differences between the factors allow to proceed to the definition of the effects of genotypes, environments and their interaction according to the following formulas and indicators:

$$
\begin{gathered}
U=1 n m \Sigma X i k ; \\
G A C_{i}=v_{i}=\frac{1}{m} X_{i}-\frac{1}{n m} \Sigma X_{i k} ; \\
d_{k}=\frac{1}{n} X_{i k}-\frac{1}{n m} \cdot \sum X_{i k ;} \\
(v d)_{i k}=x_{i k}-\frac{1}{m} X_{i}-\frac{1}{n} X_{k}+\frac{1}{n m} \cdot \sum X_{i k} ;
\end{gathered}
$$

$$
S A C_{i k}=d_{k}+(v d)_{i k}=x_{i k}-\frac{1}{m} X_{i}
$$

where $U$ is the total mean for the entire phenotypes;

$X_{i k}$ is phenotypic value of the characteristic i-th variety grown in $\mathrm{r}$-th environment;

$G A C_{i}$ is a general adaptive capacity;

$\mathrm{SAC}_{i k}$ is the specific adaptive capacity;

$d_{k}$ is the effect of k-th environment;

$(v d)_{i k}$ is an effect of interaction of i-th variety with $\mathrm{r}$ th environment;

$X_{i}$ is the sum of all phenotypes of the $\mathrm{i}$-th genotype;

$X_{k}$ is the sum of all phenotypes of k-th genotype;

$X_{i k}$ is the total sum of all phenotypes.

$\mathrm{m}$ is the number of years.

To assess the ability of the i-th genotype to interact with environments, it is necessary to use the interaction variance:

$$
\begin{aligned}
\sigma^{2}(G \cdot E)_{g i} & =\frac{1}{m-1} \Sigma(v d)_{i k}^{2}- \\
& -\frac{n m-1-m+1}{n m} \sigma^{2}
\end{aligned}
$$

As a measure of the stability of the i-th genotype, it is proposed to use the $\mathrm{SAC}_{\mathrm{i}}$ variance:

$$
\sigma^{2} S A C_{i}=\frac{1}{m-1} \Sigma\left(d_{k}+v d_{i k}\right)^{2}-\frac{m-1}{m} \sigma^{2}
$$

The relative stability of the genotype $\left(\mathrm{S}_{\mathrm{gi}}\right)$ allows comparing the results of experiments with a different set of cultures, genotypes, environments. The relative stability of the genotype is similar to the coefficient of variation when studying it in a number of environments:

$$
S_{g i}=\frac{\sigma S A C_{i}}{U+G A C_{i}} \cdot 100 \%
$$

The coefficient of variation of the relative stability of the variety is the indicator $S_{g}$, expressed in \%:

$$
S_{g}=\frac{S_{g 1}+\cdots+S_{g n}}{n}
$$

The selection value of the genotype ( $\mathrm{SVG}$ ) is determined by the formula:

$$
\begin{gathered}
S V G_{i}=U+V_{i}-P \cdot \alpha S A C_{i}, \text { where } \\
P=\frac{100}{2 S_{g}}
\end{gathered}
$$

\section{Results}

During the years of research, weather conditions both separately by years and throughout the growing season of grain sorghum plants have developed quite differently, as evidenced by the hydrothermal coefficient (HTC) and index of environmental conditions $\left(\mathrm{I}_{\mathrm{j}}\right)$ (Table 1).

Table 1. Hydrothermal coefficient, index of environmental conditions $\left(\mathrm{I}_{\mathrm{j}}\right), 2015-2018$

\begin{tabular}{|c|c|c|c|c|c|c|}
\hline \multirow{2}{*}{ Years } & \multicolumn{5}{|c|}{ Month } & \multirow{2}{*}{$\mathrm{I}_{\mathrm{j}}$} \\
\cline { 2 - 6 } & May & June & July & August & September & \\
\hline 2015 & 0.8 & 0 & 1.3 & 0.4 & 0.2 & 9.4 \\
\hline 2016 & 0.6 & 0.2 & 0.8 & 0 & 3.4 & -4.3 \\
\hline 2017 & 1.9 & 2.7 & 0.3 & 0 & 1.8 & -8.1 \\
\hline 2018 & 0.4 & 0.4 & 1.0 & 0.2 & 0.4 & 2.9 \\
\hline
\end{tabular}


In May 2015, precipitation was within normal limits mainly in the first two decades of May and conditions for field germination of sorghum seeds were favorable. In June, maximum air temperatures reached $36.5{ }^{\circ} \mathrm{C}$, there was a sharp shortage of precipitation to $54.1 \mathrm{~mm}$. However, July was cool and rainy. August and September were dry. This contributed to the good maturation of sorghum crops.

Weather conditions in 2016 were similar to 2015, but September 2016 was wet and cool and meteorological conditions of the growing season in 2016 were less favorable for sorghum $\left(\mathrm{I}_{\mathrm{j}}=-4.3\right)$.

Meteorological conditions of the growing season of 2017 were extremely unfavorable for grain sorghum $\left(\mathrm{I}_{\mathrm{j}}=-8,1\right)$. May and June were cool and rainy, but August was characterized by elevated temperatures and lack of precipitation.

Significant reserves of moisture in the soil in the spring of 2018, despite the lack of moisture in May, June, August and September, sorghum plants developed normally, and were able to form high grain yields $\left(\mathrm{I}_{\mathrm{j}}=2.9\right)$.

Thus, the agro-climatic conditions for the development of sorghum crops in the years of research were quite diverse, 2015 was very favorable, 2018 relatively favorable, 2016 unfavorable, 2017 extremely unfavorable.

Regression analysis of the relationships between the yield of varieties and lines and the hydrothermal coefficient showed that they are linear in nature with an approximation confidence $\left(\mathrm{R}^{2}\right)$ of about 0.645 , which allowed for a correlation analysis between them. Sorghum is characterized by a significant duration of the period "shoots - tillering" (May-June). During this period, there was a negative correlation between the hydrothermal coefficient and crop yield $(\mathrm{r}=-0.24--0.82)$.

This allowed for the most complete evaluation of grain sorghum varieties for plasticity and stability on the basis of "grain yield". However, during flowering and soft dough stages sorghum shows increased requirements for moisture and the higher the hydrothermal coefficient, the greater its yield with a correlation coefficient $r=$ 0.62-0.98. In September in the Middle Volga region in the period of full ripening of grain for sorghum more favorable dry conditions $(\mathrm{r}=-0.62--0.94)$.

The presence or absence of interaction "genotypeenvironment" for the whole set of studied varieties we established by the method of 2-factor analysis of dispersion data of competitive variety tests of grain sorghum. Significant effects of the environment, genotypes and their interaction on the indicator "grain yield" were revealed by the Fisher criterion (Table 2).

The main goal of the breeder when breeding new varieties is a high yield as a consequence of the actualization of the plant's genetic potential in different environmental conditions. Out of 4 years of our research, two of them were characterized by favorable, two by unfavorable conditions. According to the results of the evaluation of the yield of varieties on average for years it amounted to $35.3 \mathrm{c} \cdot \mathrm{ha}^{-1}$ and was in the range of 21.1-48.6 c $\cdot$ ha $^{-1}$ (Table 3).

Linear regression coefficients $\left(b_{i}\right)$ between yield and environmental conditions index $\left(\mathrm{I}_{\mathrm{i}}\right)$ and yield stability index $\left(\mathrm{S}_{\mathrm{di}}^{2}\right)$ show genotype responses to changes in environmental conditions and are indicators of plasticity and stability.

The peculiarities of grain yield variability were expressed by the coefficient of variation (CV). In statistics, the data set is homogeneous if the coefficient of variation is less than $33 \%$. The degree of their dispersion is average.

The linear regression coefficient $b_{i}$ shows the reaction of the genotype to changes in environmental conditions. Varieties with $b_{i}>1$ are characterized by high plasticity, respond well to the improvement of growing conditions, they require a high level of agricultural technology and are of intensive type. The variety Ros and line L-34/14 belongs to this type.

Genotypes with $b_{i}<1$ are less plastic, react poorly to changes in the environment and are classified as semiintensive. They form the highest grain yield at the minimum of expenses. The varieties Derzhavnoe, Kinelskoye 63, Slavyanka, line L-28/14 belongs to this type.

At $b_{i}=1$, there is a complete correspondence of the change in the yield of the variety to the change in the growing conditions (extensive type). The variety Premiera and line L-141/14 belongs to this type.

We evaluated the differences of varieties on the stability of the $\mathrm{S}^{2}{ }_{\text {di }}$ crop by F-criterion. In our example $\mathrm{F}_{0.5} \mathrm{t}=19$, when df $(1)=\mathrm{n}-2=2$, df $(2)=\mathrm{n}-2=2$. Varieties with $S^{2}{ }_{d}(1) / S^{2}{ }_{d}(2)>19$ differ significantly in stability, and for $\mathrm{S}_{\mathrm{d}}^{2}(1) / \mathrm{S}_{\mathrm{d}}{ }^{2}(2)<19$, the differences between them are not significant. In our experiences there were no varieties that differ significantly in stability $\left(F_{f}<F_{t}\right)$ and the variability of their yield was caused only by the influence of environmental conditions. All tested varieties were medium stable in relation to the growing conditions.

The value of the slope of the regression lines provides visual information about the differences of varieties in comparison with their average response to changes in growing conditions (Fig. 1).

According to Fig. 1, variety Derzhavnoe and line L-28/14 in adverse weather conditions (the left side of their regression lines) have a yield above average in experience (semi-intensive type). The variety Kinelskoe 63 also belongs to the semi-intensive type. It reacts poorly to changes in growing conditions, but its yield is always higher than the average in experience. 


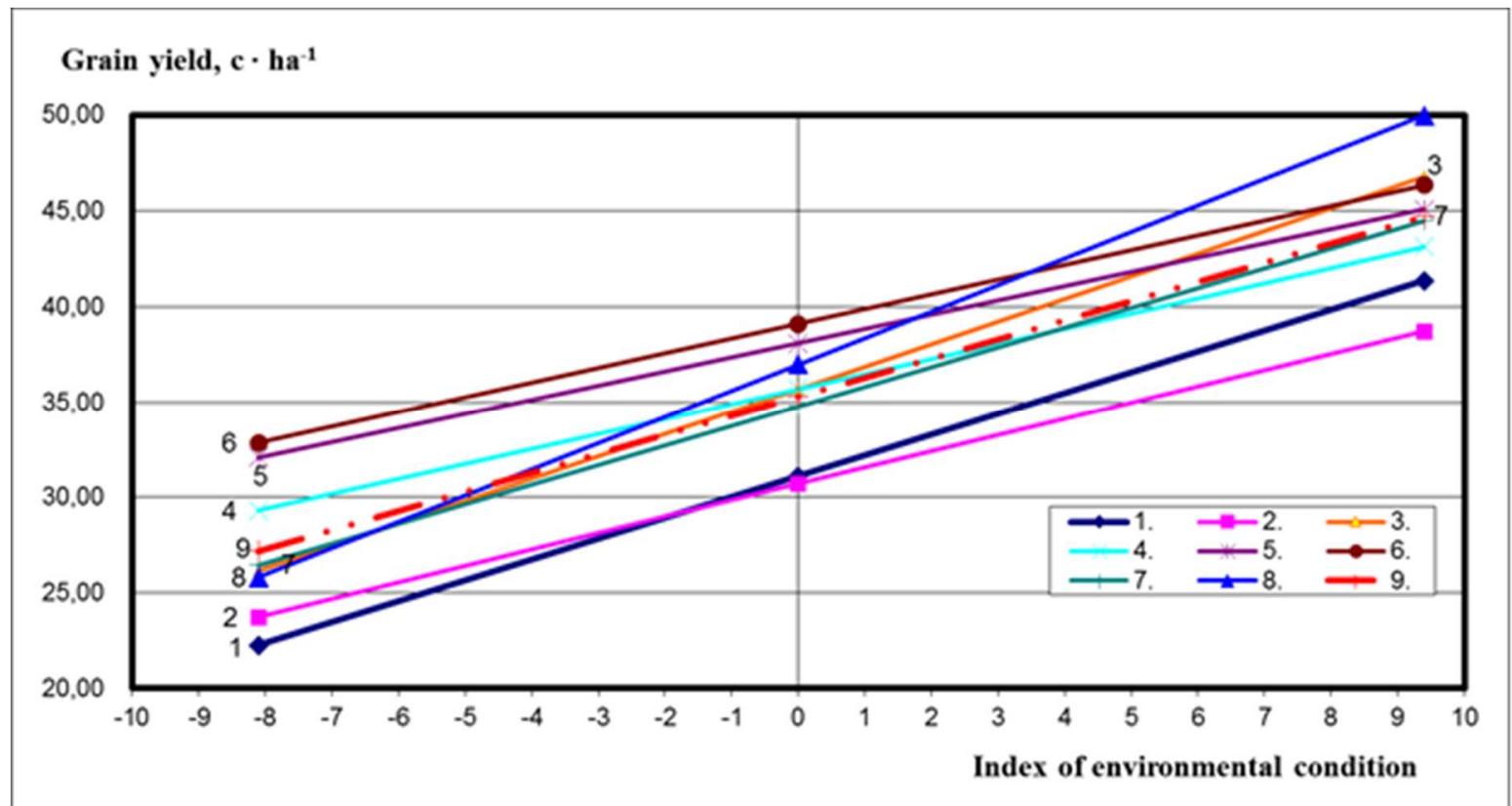

Fig. 1. Influence of changes of environmental conditions on sorghum grain yield: Varieties and hybrid lines of sorghum:

1 - Premiera; 2 - Slavyanka; 3 - Ros; 4 - Kinelskoye 63; 5 - Deszhavnoe; 6 - L-28/14; 7 - L-141/14; 8 - L-34/14; 9 - average

The regression line of the variety Premiera and the line L-141/14 runs parallel to the average in experience, its yield varies according to changes of environmental conditions (extensive type).

In the variety Ros and hybrid line L-34/14, the regression line rises high in the right part of the chart (favorable conditions) relative to the middle line and a slight decrease from the average experience in the left (adverse conditions). This indicates their high responsiveness to environmental improvements (intensive type).
Table 2. The results of the analysis of variance and the share of contributions of genotypes in the variability of the trait "grain yield"

\begin{tabular}{|c|c|c|c|c|c|c|}
\hline \multirow{2}{*}{ Dispersion } & \multirow{2}{*}{$\begin{array}{l}\text { Sum of } \\
\text { squares }\end{array}$} & \multirow{2}{*}{$\begin{array}{l}\text { Degrees } \\
\text { of } \\
\text { freedom }\end{array}$} & \multirow{2}{*}{$\begin{array}{c}\text { Average } \\
\text { square }\end{array}$} & \multicolumn{2}{|l|}{$F$} & \multirow{2}{*}{$\begin{array}{l}\text { Share, } \\
\%\end{array}$} \\
\hline & & & & actual & 05 & \\
\hline Total & 5990.7 & 95 & 5.2 & & & \\
\hline $\begin{array}{c}\text { Genotipe } \\
\text { (variety) }(\mathrm{A})\end{array}$ & 780.7 & 7 & 111.5 & 17.0 & 2.2 & 13.0 \\
\hline $\begin{array}{c}\text { Environment } \\
\text { (B) (year) }\end{array}$ & 4330.2 & 3 & 1443.4 & 220.4 & 2.8 & 72.3 \\
\hline $\begin{array}{l}\text { Interaction } \\
(\mathrm{A} \times \mathrm{B})\end{array}$ & 463.5 & 21 & 22.1 & 3.4 & 1.7 & 7.7 \\
\hline Remainder & 406.0 & 62 & 6.6 & & & 6.8 \\
\hline
\end{tabular}

Table 3. Grain yield, evaluation of varieties of grain sorghum on the parameters of plasticity and stability by S.A. Eberhart et al., 2015-2018

\begin{tabular}{|c|c|c|c|c|c|c|c|c|c|c|}
\hline \multirow[t]{2}{*}{ Variety, line } & \multicolumn{5}{|c|}{ Year, yield, $\mathrm{c} \cdot \mathrm{ha}^{-1}$} & \multirow{2}{*}{$\begin{array}{l}\text { Coefficient } \\
\text { of variation, } \\
(\mathrm{CV})\end{array}$} & \multicolumn{2}{|c|}{ Parameters } & \multicolumn{2}{|c|}{$\begin{array}{c}\text { Variety } \\
\text { assessment }\end{array}$} \\
\hline & 2015 & 2016 & 2017 & 2018 & average & & $\mathrm{b}_{\mathrm{i}}$ & $\mathrm{S}_{\mathrm{di}}^{2}$ & plasticity & Stability \\
\hline Premiera & $42.0 \pm 3.2$ & $28.4 \pm 0.8$ & $21.1 \pm 2.0$ & $32.7 \pm 0.8$ & 31.1 & 19.7 & 1.09 & 4.09 & medium & \multirow{8}{*}{$\underset{\Xi}{\Xi}$} \\
\hline Slavyanka & $38.6 \pm 2.3$ & $28.2 \pm 2.7$ & $22.5 \pm 1.4$ & $33.4 \pm 1.9$ & 30.7 & 19.9 & 0.86 & 1.52 & low & \\
\hline Ros & $48.6 \pm 2.4$ & $30.3 \pm 1.3$ & $27.1 \pm 2.2$ & $36.6 \pm 2.4$ & 35.7 & 17.2 & 1.18 & 5.33 & high & \\
\hline Kinelskoye 63 & $43.6 \pm 2.7$ & $34.4 \pm 0.7$ & $27.9 \pm 2.2$ & $36.9 \pm 2.0$ & 35.7 & 17.2 & 0.79 & 3.88 & low & \\
\hline Derzhavnoe & $46.0 \pm 1.6$ & $32.1 \pm 1.2$ & $34.2 \pm 3.2$ & $40.2 \pm 1.9$ & 38.12 & 16.1 & 0.74 & 6.66 & low & \\
\hline L-28/14 & $47.1 \pm 1.8$ & $32.1 \pm 1.1$ & $35.5 \pm 3.4$ & $41.7 \pm 2.6$ & 39.1 & 15.7 & 0.77 & 10.67 & low & \\
\hline L-141/14 & $43.2 \pm 2.3$ & $30.0 \pm 2.4$ & $25.6 \pm 1.9$ & $40.3 \pm 0.7$ & 34.8 & 17.6 & 1.03 & 4.37 & medium & \\
\hline L-34/14 & $48.3 \pm 2.3$ & $32.6 \pm 2.1$ & $23.5 \pm 1.0$ & $43.4 \pm 1.1$ & 37.0 & 16.5 & 1.38 & 8.44 & high & \\
\hline $\mathrm{LSD}_{05}$ & 3.80 & 3.01 & 2.06 & 2.40 & 3.99 & - & - & - & - & - \\
\hline $\begin{array}{c}\text { Average } \\
\text { experience }\end{array}$ & - & - & - & - & 35.25 & & 1.0 & - & - & - \\
\hline $\mathrm{I}_{\mathrm{j}}$ & 9.4 & -4.3 & -8.1 & 2.9 & - & & - & - & - & - \\
\hline
\end{tabular}

Indicators of adaptive capacity and stability of sorghum varieties were evaluated by A.V. Kilchevsky and L.V. Khotyleva [1] (Table 4).

They propose to carry out the selection on the general adaptive capacity (GAC) for several environments, taking into account the stability and specific adaptive capacity (SAC) in a particular environment (indoor soil, irrigation and others). The highest values of GAC and the maximum average grain yield were observed in the variety Derzhavnoe and lines L-28/14 and L-34/14. The

\footnotetext{
* Corresponding author: antimonovaolga@list.ru
} 
relative stability of the $S_{\text {gi }}$ genotype is similar to the coefficient of variation of $\mathrm{V}$ when studied in a number of media. Then, the varieties Kinelskoe 63, Derzhavnoye, L-28/14 is prone to medium environmental variability and more stable, the rest are significant and less stable. The indicator selection value of the genotype $\left(\mathrm{SVG}_{\mathrm{i}}\right)$ is used for the selection of varieties that combine productivity and stability. In our experiment, this indicator is the highest in the varieties: Kinel 63, Derzhavnoe and line L-28/14. The genotype compensation coefficient $\left(\mathrm{K}_{\mathrm{gi}}\right)$ is used in the selection of stable genotypes. The lower the value of this coefficient the more stable the genotype.

$\mathrm{K}_{\mathrm{gi}}$ is less than 1.0 in varieties Slavyanka, Kinelskoye 63, Derzhavnoe, line L-28/14, which testifies to their stability. The varieties Premiera, Ros, lines L-141/14 and L-34/14 have a compensation coefficient above 1.0, which indicates the presence of a destabilization effect. According to the nonlinearity coefficient $\left(\mathrm{L}_{\mathrm{gi}}\right)$, all genotypes have linear responses to the environment.

Table 4. Parameters of adaptive ability and stability according to A.V. Kilchevsky and L.V. Khotyleva, 2015-2018

\begin{tabular}{|l|l|l|l|l|l|l|l|}
\hline Variety, line & $\bar{x}_{\mathrm{i}}$ & $\mathrm{GAC}_{\mathrm{i}}$ & $\sigma^{2}$ SAC $\mathrm{i}$ & $\mathrm{S}_{\mathrm{gi}}, \%$ & $\mathrm{SVG}_{\mathrm{i}}$ & $\mathrm{K}_{\mathrm{gi}}$ & lgi \\
\hline Premiera & 31.1 & -4.25 & 74.37 & 27.76 & 12.00 & 1.27 & 0.02 \\
\hline Slavyanka & 30.7 & -4.63 & 45.72 & 22.04 & 15.73 & 0.78 & 0.01 \\
\hline Ros & 35.7 & 0.35 & 88.26 & 26.34 & 14.90 & 1.51 & 0.02 \\
\hline Kinelskoye 63 & 35.7 & 0.40 & 40.12 & 17.73 & 21.71 & 0.69 & 0.08 \\
\hline Derzhavnoe & 38.12 & 2.83 & 37.65 & 16.10 & 24.56 & 0.64 & 0.16 \\
\hline L-28/14 & 39.1 & 3.80 & 42.55 & 16.62 & 24.73 & 0.73 & 0.19 \\
\hline L-141/14 & 34.8 & -0.53 & 67.81 & 23.67 & 16.58 & 1.16 & 0.02 \\
\hline L-34/14 & 37.0 & 1.67 & 121.57 & 29.85 & 12.58 & 2.08 & 0.11 \\
\hline $\mathrm{S}_{\mathrm{g}}$ & & & 22.58 & & & & \\
\hline
\end{tabular}

\section{Discussion}

According to the results of this study that used weather forecasting to simulate yield parameters of sorghum, that the year-to-year variation had the greatest impact on the grain yield of sorghum $(72.3 \%)$, the characteristics of the variety determined the manifestation of the sign by $13.0 \%$. The "year $\mathrm{x}$ variety" interaction contributed to the overall yield variability of $6.8 \%$.

Thus, in the forest-steppe of the Middle Volga region, the sorghum yield is higher, the more precipitation and hydrothermal coefficient in July during the flowering and soft dough stages of the crop and the less precipitation in September during the physiological maturity of the grain with an average correlation coefficient of 0.953 and -0.753 , respectively.

As for ecological plasticity and stability in relation to growing conditions, the tested varieties and hybrid lines of sorghum belonged to medium-stable and mediumplastic, intensive (Ros, L-34/14), semi-intensive (Derzhavnoye, Kinelskoye 63, Slavyanka, L-28/14) and extensive (Premiera, L-141/14) types. Semi-intensive varieties of grain sorghum form the highest yield with a minimum of costs. In varieties of the extensive type, there is a correspondence of changes in the yield of the variety and the growing conditions. The line L-28/14 belongs to the group of medium-plastic and unstable genotypes.

\section{Conclusion}

When assessing the relationship between a genotype and environmental conditions, variety Derzhavnoe and lines L-28/14, L-34/14 differed most in the indicators of general adaptive capacity and yield stability, apparently due to their complex resistance to adverse abiotic factors. Promising line L-28/14, which combines high productivity and environmental stability, is recommended for transfer to the state variety testing.

The research work was carried out in accordance with the Program of fundamental scientific research of the state academies of sciences for 2013-2020 on the theme: "Create a new highly productive, breeding material of sorghum crops for arid conditions of the Middle Volga region by the method of interline hybridization".

The authors declare there are no conflicts of interest.

\section{References}

1. A.V. Kilchevsky, L.V. Khotyleva, Genet. J., 21(9), 1481-1497 (1985)

2. A.A. Zhuchenko, Proc. of Int. Sci. Conf., 10-16 (Saratov, 2004)

3. O.S. Korzun, A.S. Bruylo, Adaptive features of breeding and seed production of agricultural plants (SSAU, Grodno, 2011)

4. Yu.N. Gorelov, Encyclopedia of the Samara region 1(A-V) (Samara, 2010)

5. B.N. Malinovsky, A.V. Alabushev, Bull. of Agric. Sci., 12, 12-80 (1987)

6. N.A Klyuchnikov, Corn and sorghum, 2, 12-13 (2000)

7. A.V. Alabushev, Sorghum (selection, seed production, technology, economics) (Book, Rostovon-Don, 2003)

8. A.K. Antimonov, L.F. Syrkina, O.N. Antimonova et al., Mater. of the All-Russ. Sci.-pract. Conf., pp. 66-70 (Samara, 2013)

9. A.K. Antimonov, V.V. Glukhovtsev, L.F. Syrkina, O.N. Antimonova, News of the Orenburg Agric. Univ., 3(47), 37-39 (2014)

10. P.P. Litun, pp. 63-93 (Naukova Dumka, Kiev, 1980)

11. S.A. Eberchart, W.A. Russel, Crop Sci., 6(1), 36-40 (1966). DOI: $10.2135 /$ cropsci 1966. 011183x000600010011x

12. V.A. Sapega, Bull. of Agricultural Science of Kazakhstan, 10, 24-28 (1988)

13. R.A. Udachin, A.P. Golovochenko, Select. and seed product., 5, 2-6 (1990)

14. O.P. Cybalnik, G.I. Kostina, D.S. Syumin, Agrar. Bull. of the Southeast, 3, 64-67 (2010)

15. A.Yu. Surkov, Legum. and cereal crops, 1(9), 63-67 (2014)

16. I.Yu. Nikiforova, Legum. and cereal crops, 1(13), 79-83 (2015) 
17. G.N. Karazhbey, Sort. and protect. of rights to plant variet., 2(13), 150-154 (2017). DOI: 10.21498/2518-1017.13.2.2017.105396

18. E.V. Stolpivskaya, L.A. Kukushkina, Yu.N. Zemlyankina, V.V. Vukolov, News of the Samara Sci. Center of the Rus. Acad. of Sci., 2(4), 692-695 (2018)

19. K.E. Comstock, K.H. Moll, NAS-NGC, 982, 164-196 (1963)

20. K.W. Finlay, G.N. Wilkinso Austral. J. Agr. Res, 14(2), 742-754 (1963). DOI: 10.1071/AR9630742

21. N. Kishore, L.N. Singh, Indian J. of Genet., 64(1), 71-72 (2004)

22. Adugna, Afric. Crop Sci. J., 15(2), 83-92 (2007)

23. F.A. Showemimo, Commun. Biometry Crop Sci., 2(1), 68-73 (2007)
24. E.M. Ezzat, M.A. Ali, A.M. Mahmoud, Asian J. of Crop Sci., 2(4), 250-260 (2010). DOI: 10.3923/ajcs.2010.250.260

25. S. Rakshit, K.N. Ganapathy, S.S. Gomashe et al., Agricult. Sci., 155(1), 44-59 (2017). DOI: 10.1017/S0021859616000137

26. A.M.M. Al-Naggar, R.M. Abd El-Salam, M.R.A. Hovny, Y.S. Walaa, Asian J. of Agric. and Horticul. Res., 1(3), 1-14 (2018). DOI: 10.9734/AJAHR/2018/40985

27. M. Hamidou, O. Souleymane, M. Niango Ba et al., Plant Genet. Resour.: Characterizat. and Utilizat., 17(1), 81-86 (2019). DOI: 10.1017/S1479262118000382

28. P.R. Patel, S.K. Jain, R.M. Chauhan, P.T. Patel, Electr. J. of Plant Breed, 10(2), 353-363 (2019). DOI: 10.5958/0975-928X.2019.00045.0 